\title{
THE SERVICE INNOVATION CHALLENGE
}

\author{
Roberta Sebastiani *
}

The relevance of services in economies is increasing and is progressively affecting their economic growth because of the critical influence of services on GDPs (Figure 1). By the 2013 services accounted for almost three-fourths of world GDP, up from about half in the 1980s and the trend is still rising.

Service innovation appears to be an explanation and a key driver for this growth since it aims at creating new value through service design and delivery as well as new business models.

Service innovation is a multidimensional construct that in today's service-centered economy has been the objective of a growing consideration both from researchers and practitioners (Ordanini and Parasuraman, 2011).

Early approaches at service innovation, fostered by the emergence of the industrial innovation theory in economics, emphasized the centrality of technological development and scientific improvements also in the case of services: technology-driven innovation and consequent efficiency gains are still founding arguments in services innovation literature, a major topic in service diffusion, development and sustainability (Gallouj and Savona, 2009).

Nevertheless, as Gallouj and Weinstein pointed out, non-technological service-oriented innovation studies acknowledge that "innovation can exist where the 'technologist gaze' perceives nothing" (1997: 538). This is the

* Associate Professor, Università Cattolica del Sacro Cuore Via Necchi 5, 20123 Milano, e-mail: roberta.sebastiani@unicatt.it.

Mercati e Competitività n. 2, 2015 
Fig. 1 - Services, etc., value added (\% of GDP)

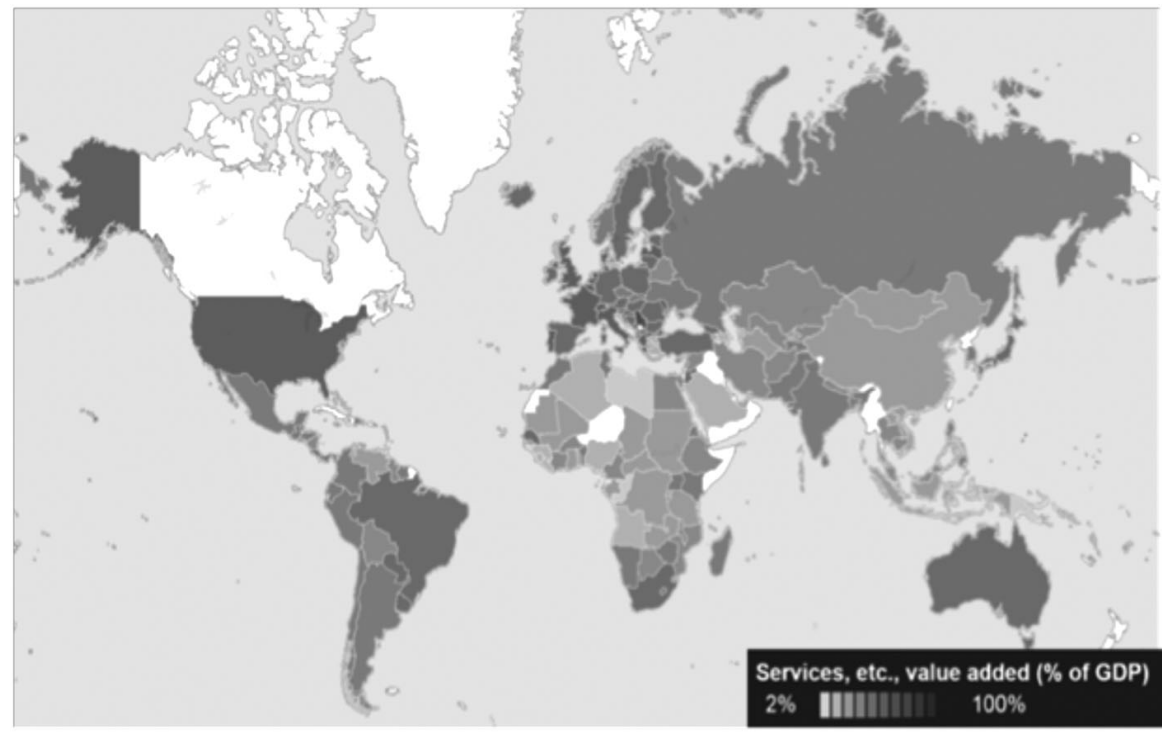

Source: The World Bank.

reason why, also in recent years, some scholars - although recognizing the importance of early streams of research - have pointed out the need to invest in better comprehension of service innovation (Metcalfe and Miles, 2000).

From the early 90s, we observe a significant development in studies on service innovation, whose aim was to redefine the conceptualization and the measurement of innovation in order to create an "autonomous" (or "distinctive") approach able to capture the specificity of services in the processes of innovation, aside from the technological dimension. In fact, they assume that the innovation approach differs intrinsically from the archetype of innovation in manufacturing because services are different from manufacturing and have different effects on innovation processes. While the "autonomous" approach has had the great merit of highlighting some strategic factors for innovation in services, at the same time it has generated a heated debate on its capability to represent the real dynamics of innovation in firms.

The subsequent evolution of the body of contributions on this topic has seen the emergence of a new approach, an "integrative" view in which technology is integrated with the other aspects of innovation. Representing a sort of synthesis of the first two approaches, it aims at overcoming the traditional dichotomy between manufacturing and services, by considering innovation as an integral process that is 
independent from the specific context. On the one hand, it recognizes that "external" technologies are instrumental in stimulating supply and, on the other hand, that companies rarely assume a passive role in adopting a new technology. Furthermore, the wide range of technologies that are either already available or under development, creates an enormous number of possible uses that cannot be easily defined ex-ante: this suggests that innovation cannot be restricted to the adoption of new technologies, but instead must be conceived as a creative use of technology in order to interpret the market or integrate the knowledge of the supply chains, thus increasing companies' control, management and replication of innovation processes. The integrative or "synthesis" approach reflects the growing complexity and multidimensionality of innovation processes (Carlborg et al., 2013). The focus is increasingly shifting from technology (and its implications) to knowledge, from the single actions to the interrelated activities underlying innovation in services.

The picture we have drawn here testifies that innovation in services is a complex matter and that it requires an inter-disciplinary approach. Even though the topic still lacks a general frame of interpretation, there is a general acknowledgement of the relevance of innovation for services and a broader frame of evolution of this stream of research can be identified (Rubalcaba et al., 2012).

Recent efforts have contributed to open a new perspective over service innovation by emphasizing the relevance of: organization structure and culture (Normann, 2001; de Jong and Vermeulen, 2003; Gustafsson and Johnson, 2003); non-technological competences and skills (Sundbo et al., 2006; Tether, Howells, 2007); customers integration in the value creation process (Prahalad and Ramaswamy, 2004; Vargo and Lusch, 2008; Edvardsson et al., 2011); and interrelations between organizations and networks (Agarwal and Selen, 2009).

Lusch and Nambisan (2015) provide a broader view of the concept of service innovation in terms of "re-bundling of diverse resources that create novel resources that are beneficial (i.e., value experiencing) to some actors in a given context". This view of service innovation breaks free from the provider-customer dichotomy that is highly emphasized in service research.

As a matter of fact, service innovation does not occur in isolation but is enabled collectively in the process of interaction and is manifested in the consequences for participants in the context of relational interaction. It thus can be interpreted as the outcome of networks in which different actors interact to co-create service innovation and it occurs in interactive configurations of mutual exchange, namely service systems (Vargo et al., 2008), characterized by diverse economic, social and cultural contexts. 


\section{R. Sebastiani}

Companies are dealing with the challenge of establishing and managing relationships and interactions among the actors, using and combining resources, and performing activities in order to increase the value created by the network(s).

Furthermore the relational context is not a given entity. It is shaped by individuals acting in interactions and guided by a set of drivers of value from time to time different, depending on the space-time context of the subjects.

Starting from these considerations, what emerges is that future research should adopt a multidimensional and interdisciplinary approach.

If we consider service innovation at a service system-level and occurring when service systems are enabled to co-create value differently, several key questions emerge.

As a starting point, researchers should focus on how innovation occurs within service systems and value networks. Which type of complexity are companies facing when developing innovation in service systems? How are they dealing with a relational context in continuous evolution?

In this regard, recent studies have highlighted the importance of investigating innovation in service systems at the micro level, focused on interaction among a limited number of actors, at the meso level, involving a diverse set of actors organized around a shared approach to develop innovation (i.e.a network or an industry), and at the macro level, related to cultures or societies (Lusch and Vargo, 2014; Witell et al., 2015); the adoption of this perspective provides the opportunity to better understand how companies arrange common organizational structures and sets of principles to facilitate resource integration and service exchange among the different actors, since service systems are considered relatively selfcontained, self-adjusting systems of resource-integrating actors connected by shared institutional logics and mutual value creation through service exchange (Vargo and Lusch, 2011).

In this line, the need emerges for more in-depth investigation of the effects that an innovation may have not only on the individual or the organization, but also on society. It implies adopting a more comprehensive, systemic, and social approach to service innovation, in order to consider more social implications of service innovation and to include different actors, such as public entities. The aim is also to highlight the transformative power of service innovation on society and on global systemic values.

As service innovation issues pose new challenges to researchers and practitioners, they require the development of new theories, the adoption of new methodologies and the outlining of new empirical settings. By adopting a synthesis approach, as highlighted above, it is possible to 
combine existing methods and tools with new and specific ones that might offer a better view of the service innovation challenge and reality.

\section{References}

Agarwal R., Selen, W. (2009). Dynamic capability building in service value networks for achieving service innovation. Decision sciences, 40 (3): 431-475, doi: 10.1111/j.15405915.2009.00236.x.

Carlborg P., Kindström D., Kowalkowski C. (2014). The evolution of service innovation research: a critical review and synthesis. The Service Industries Journal, 34: 5, 373-398, doi: 10.1080/02642069.2013.780044.

de Jong J.P.J., Vermeulen P.A.M. (2003). Organizing successful new service development: a literature review. Management Decision, 41 (9): 844-858, doi: 10.1108/00251740310491706.

Edvardsson B., Tronvoll B., Gruber T. (2011). Expanding Understanding of Service Exchange and Value Co-Creation: A Social Construction Approach. Journal of the Academy of Marketing Science, 39 (2): 327-339, doi: 10.1007/s117470100200y.

Gallouj F., Savona M. (2009). Innovation in Services: A Review of the Debate and a Research Agenda. Journal of Evolutionary Economics, 19 (2): 149-172, doi: 10.1007/s0019100801264.

Gallouj F., Weinstein O. (1997). Innovation in Services. Research Policy, 26 (4-5): 537-556, doi: 10.1016/S00487333(97)000309.

Gustafsson A., Johnson M.D. (2003). Competing in a Service Economy: How to Create a Competitive Advantage through Service Development and Innovation. San Francisco, CA: Jossey-Bass.

Lusch R.F., Nambisan S. (2015). Service Innovation; A Service-Dominant Logic Perspective. MIS Quarterly, 39 (1): 155-175.

Lusch R.F., Vargo S.L. (2014). Service-Dominant Logic: Premises, Perspectives, Possibilities. Cambridge, UK: Cambridge University Press.

Metcalfe S., Miles I. (eds) (2000). Innovation Systems in the Service Economy. Dordrecht: Kluwer.

Normann R. (2001). Reframing Business: When the Map Changes the Landscape. Chichester: Wiley.

Ordanini A., Parasuraman A. (2011). Service innovation viewed through a servicedominant logic lens: a conceptual framework and empirical analysis. Journal of Service Research, 14 (1): 3-23, doi: 10.1177/1094670510385332.

Prahalad C.K., Ramaswamy V . (2004). The Future of Competition: Co-creating Unique Value with Customers. Boston, MA: Harvard Business School Press.

Rubalcaba L., Michel S., Sundbo J., Brown S. W., Reynoso J. (2012). Shaping, Organizing, and Rethinking Service Innovation: a Multidimensional Framework. Journal of Service Management, 23 (5): 696-715, doi: 10.1108/09564231211269847.

Sundbo J., Gallina A., Serin G., Davis J. (eds) (2006). Contemporary Management of Innovation: Are we asking the right questions?. Basingstoke: Palgrave Macmillan.

Tether B.S., Howells J. (2007). Changing understanding of innovation in services: from technology adoption to complex complementary changes to technologies, skills and organisation, DTI Occasional Paper No. 9. Innovation in Services, London: Department of Trade and Industry. 
Vargo S.L., Lusch R.F. (2008). Service-dominant logic: continuing the evolution. Journal of the Academy of Marketing Science, 36 (1): 1-10, doi: $10.1007 / \mathrm{s} 1174700700696$.

Vargo S.L., Lusch R.F. (2011). It's all B2B...and beyond: Toward a systems perspective of the market. Industrial Marketing Management, 40 (2): 181-187, doi: 10.1016/j.indmarman.2010.06.026.

Vargo S.L., Maglio P.P., Akaka M.A. (2008). On value and value co-creation: A service systems and service logic perspective. European Management Journal, 26: 145-152, doi: 10.1016/j.emj.2008.04.003.

Witell L., Anderson L., Brodie R., Colurcio M., Edvardsson B., Kristensson Per., Lervik-Olsen L., Sebastiani R., Wallin Andreassen T. (2015). Exploring dualities of service innovation: Implications for service research. Journal of Services Marketing. Forthcoming. 